Brit. Heart f., 1969, 31, 623.

\title{
Indications for High Chest Leads in Ischaemic Heart Disease ${ }^{\star}$
}

\author{
E. FLETCHER, P. MORTON, S. LAL, AND G. MURTAGH $\dagger$ \\ From the Cardiovascular Unit, Belfast City Hospital
}

Unipolar chest leads recorded in various positions higher on the chest wall, in addition to the conventional leads $V 1$ to $V 6$, have been recommended from time to time by various authors for the recognition of underlying ischaemic heart disease (Rosenbaum, Wilson, and Johnston, 1946; Holtzmann, 1952; Prinzmetal, Kannamer and Massumi, 1957). They are most useful when the routine chest leads are normal, but hitherto there has been little guidance as to when they should be recorded. In our patients the high chest leads were recorded in the third intercostal space at locations perpendicular to leads V1 to V6. We were alerted to record them by certain primary reciprocal $\mathrm{T}$ wave changes noted in the standard limb leads which are described below. Eighteen cases of high lateral infarction were thus defined. In addition, 818 standard 12-lead tracings recorded from 332 cases of proven ischaemic heart disease over a period of five years were examined to estimate the incidence of these $T$ wave changes in the limb leads during the evolution of myocardial infarction, when high chest leads may confirm that the area of infarction involved a high location in the ventricles. These $T$ wave changes and the basis for interpretation of the high chest leads employed are now defined.

Primary Reciprocal T Wave Changes in Limb LEADS AS INDICATION FOR High ChEST LEADS WHEN Conventional Chest Leads are Normal

In antero-lateral wall ischaemia the $T$ wave vector rotates rightwards from the mean $Q R S$ vector so that the QRS/T angle is abnormally widened in the frontal plane (Grant, 1957). When the ischaemic area is extensive as an antero-lateral infarction, the $T$ wave vector usually rotates more

Received March 12, 1969.

$\star$ This paper was the subject of a preliminary communication to British Cardiac Society, April 18, 1968: "The Electrocardiographic Triad of High Lateral Infarction".

t In receipt of a research award, British Heart Foundation. than 90 degrees and it is projected in lead $I$ as a negative $T$ wave. When the area of ischaemia is small, however, it may be rotated to just less than 90 degrees so that the polarity of its component in lead I remains positive but diminished in voltage. At the same time the projections of the $T$ wave vector on leads III and aVF will be increased, and aVL will have a negative $T$ wave. Thus, a reciprocal $\mathrm{T}$ wave pattern emerges, described as TI < TIII, TaVL negative, and TaVF high. As early as 1943, Dressler noted that TI $<$ TIII might be associated with anterior infarction. Moreover, these $\mathrm{T}$ wave changes were part of the triad of high lateral infarction described by Roesler (1959). We wish to add an important qualification to the observations of these authors, namely, that in order to be meaningful for the recognition of ischaemic heart disease, these reciprocal $T$ wave changes must be related to the position of the mean QRS axis. Goldberger (1947) had correctly noted that TI $<$ TIII, TaVL negative, and TaVF high could occur in the normal heart. However, these reciprocal $T$ wave changes are likely to be physiological only when the mean QRS vector is rotated rightwards, as in the illustration given by that author. We have used these reciprocal $T$ wave changes as an indication for high chest leads when the conventional chest leads are normal, especially when the amplitude of the $R$ deflection in lead I exceeds that in lead III.

High Chest Leads. The appendix of a paper by Prinzmetal et al. (1957) defines the normal high chest leads in the third intercostal space. Briefly, the "negative $T$ wave area" is confined to high leads V1 to V3, so that a negative $T$ wave in high lead V4 indicates ischaemia, and the " $Q$ area" $(Q$ deflection measuring at least $0.04 \mathrm{sec}$. in duration) seldom involves the high lead positions in health.

The clinical and cardiographic findings of 12 men and 6 women, whose ages ranged from 40 to 60 
TABLE I

CLINICAL AND CARDIOGRAPHIC CHANGES IN HIGH INFARCTION

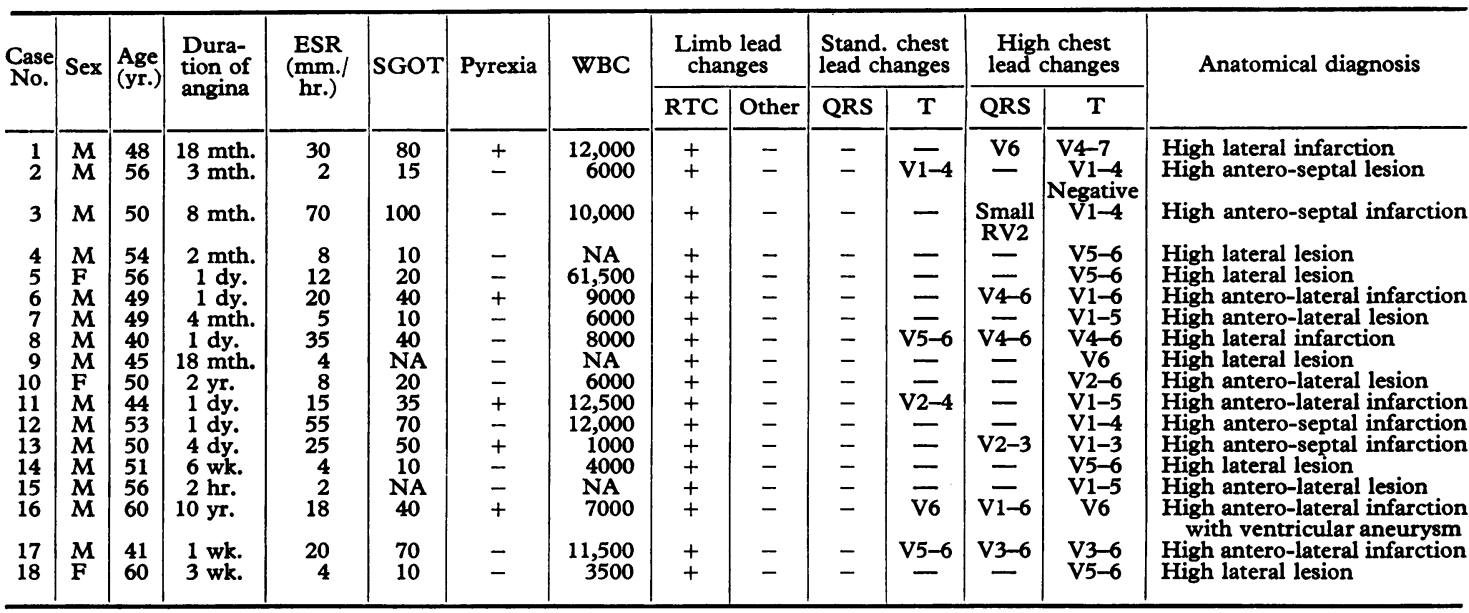

RTC = Reciprocal T wave changes (TI < TIII, TaVL negative, TaVF high).

NA $=$ Not available

years, who were referred for assessment on account of chest pain, are summarized in Table I. They were normotensive at the time of examination and auscultatory findings were normal. Radiological examination showed a ventricular aneurysm in Case 16 located at the base of the antero-lateral wall of the ventricles. All of them showed reciprocal $\mathrm{T}$ wave changes in the limb leads, with the $R$ voltage in lead I greater than in lead III, and no other abnormality. In 12 cases the standard chest leads were normal, and in 6 cases these leads showed only minimal changes in shape or voltage of the $T$ waves which by themselves would not be conclusive for the diagnosis of myocardial ischaemia (Cases 2, 8, $11,13,16$, and 17). High chest leads were, therefore, recorded. In no instance was an abnormal $Q$ deflection present in the standard chest leads. In contrast, the high chest leads all showed ischaemic $T$ wave changes, and 7 of them showed abnormal QRS changes due to infarction (Cases 1, 3, 6, $8,13,16$, and 17). The topography of the underlying lesion has been arbitrarily classified according

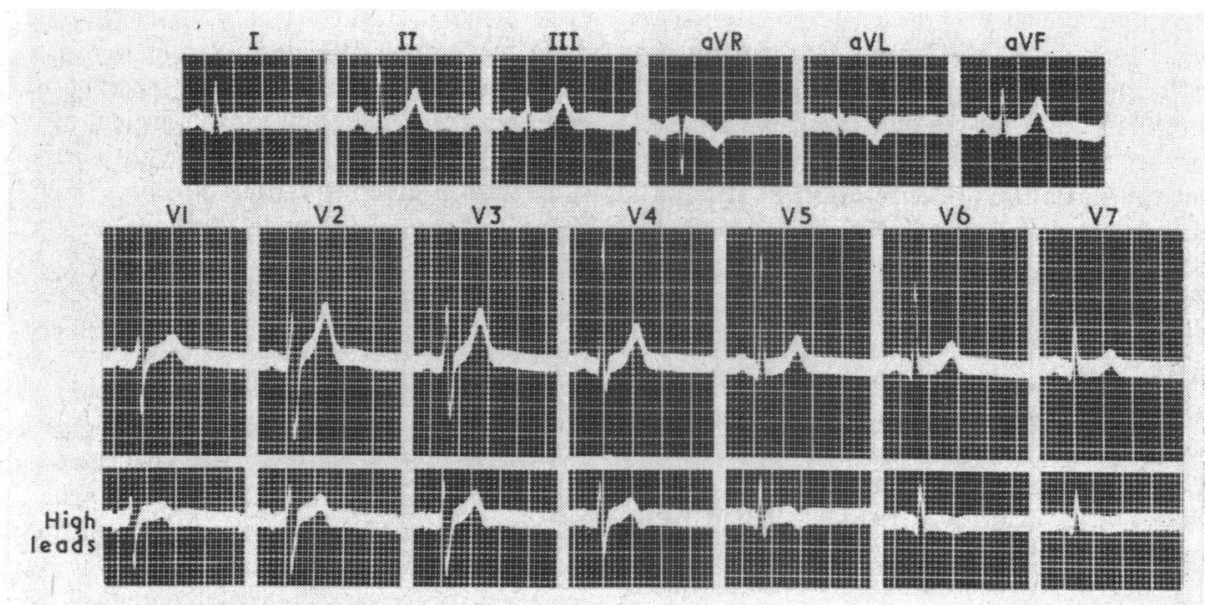

Fig. 1.-Case 1 (Table I). Recent high lateral infarction. Recorded the day after a severe attack of substernal pain. Note that conventional chest leads are normal, including lead V7. Note that $T$ waves in limb leads are abnormal, TI < TIII, TaVL negative, TaVF high, and the $R$ voltage in lead I is greater than in lead III. High leads V4 to V6 in third intercostal space confirm high lateral infarction, with negative $T$ waves, and a $Q$ deflection in lead V6 measuring 0.04 sec. in duration. 


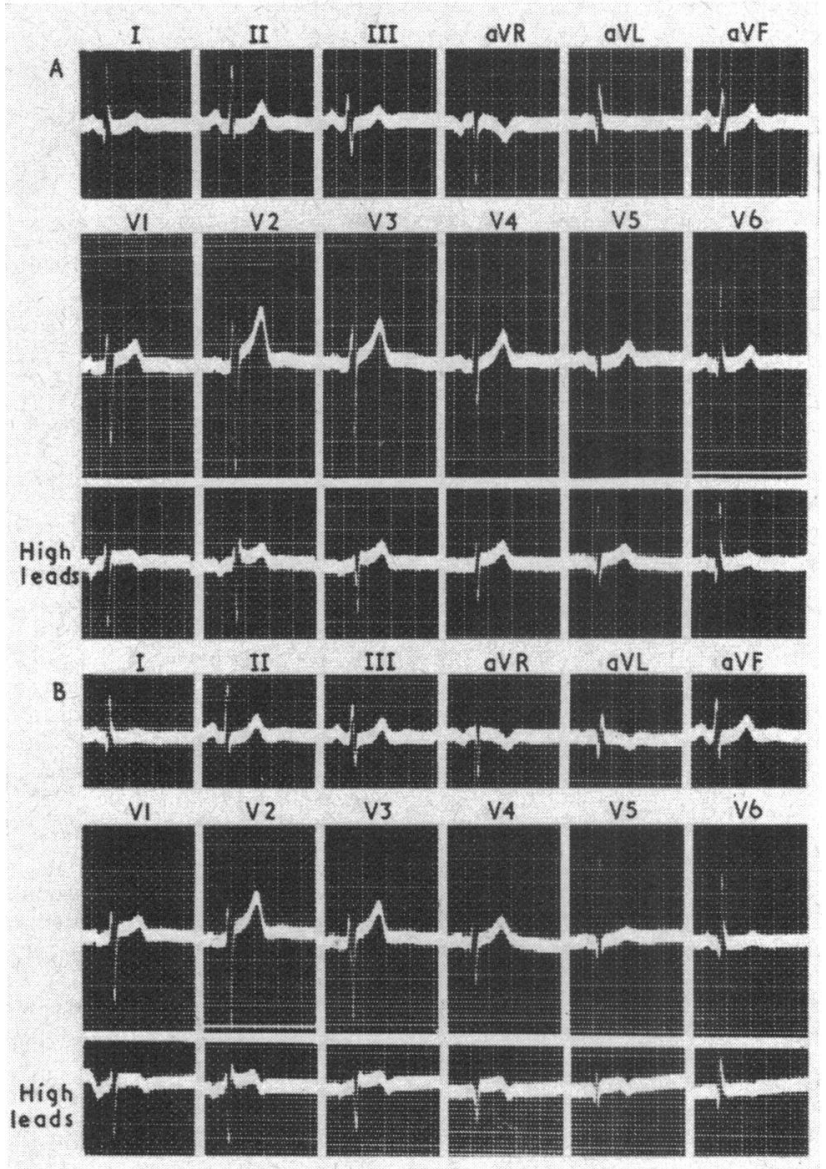

FIG. 2.-Case 6 (Table I). High antero-lateral infarction. Tracing B was recorded at acute phase of infarction, and tracing A 20 weeks later. Note that the conventional chest leads are normal. The limb leads show TI < TIII, TaVL negative, and TaVF high, and the R deflection in lead I greater than lead III. These changes are more conspicuous in tracing $B$. The high chest leads were recorded in the third intercostal space. Note the signs of recent infarction in the high leads in tracing $B$, with negative $T$ waves in all the leads, and abnormal $Q$ deflections in high leads V4 and V5. In tracing $A$, the $T$ wave polarity has been corrected, and the only residual QRS abnormality of the infarction is a low $R$ deflection in high lead V3 compared with leads to the right.

to the high leads involved, as high antero-septal, high lateral, and high antero-lateral. It is important to note that angina pectoris may be present for weeks or months before the patient is referred for assessment. Whether or not myocardial necrosis is present depends upon correlation of clinical, pathological, and cardiographic data at the time of examination. It was apparently present and due to fresh infarction in Cases 1, 3, 6, 8, 11, 12, 13, 16, and 17, in view of the associated pyrexia, raised erythrocyte sedimentation rate, and serum enzyme levels. Nevertheless, the area of infarction is likely to be small in the high lateral positions, which explains the relatively benign clinical course provided that extension of the infarction to more conventional locations does not occur. Representative tracings illustrating the reciprocal $T$ wave changes in the limb leads and the diagnostic importance of the high chest leads are given in Fig. 1 to 3.

\section{Discussion}

Unless the attending physician in hospital practice specifically requests additional high chest leads, routine cardiograms are likely to include only the arbitrarily chosen standard chest leads. A review of published records, however, reveals that the reciprocal $T$ wave changes described above were present in 42 of 49 cases of high infarction, i.e. 


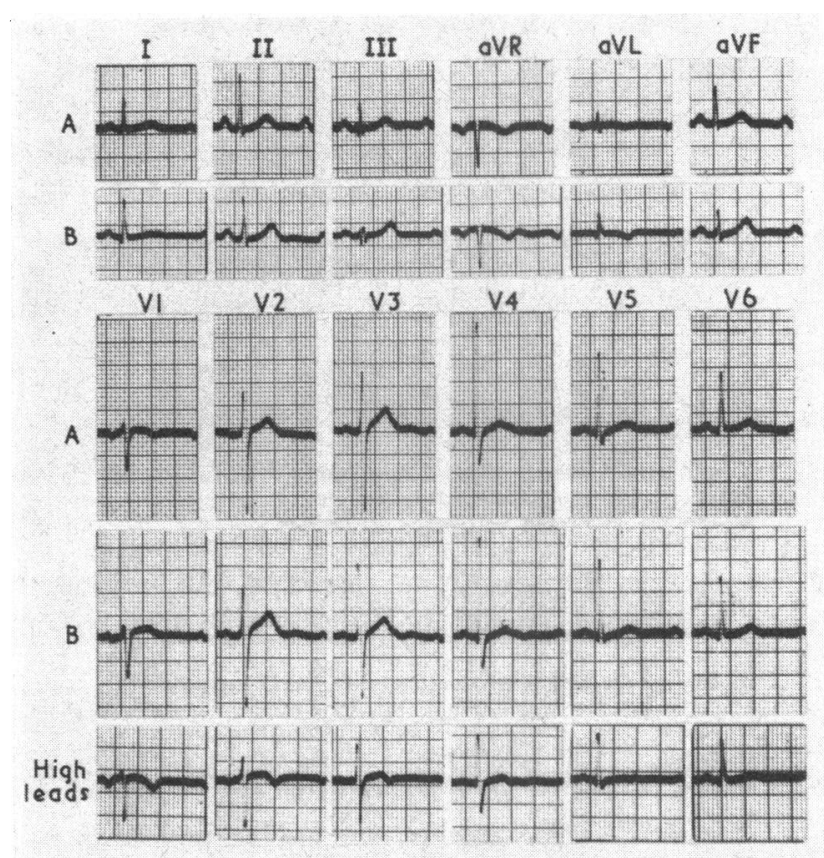

FIg. 3.-Case 11 (Table I). High antero-lateral infarction. Tracing A was recorded five months before tracing B. The high chest leads in the third intercostal space were recorded with tracing B when the patient was referred for severe chest pain on the previous day. Note that the standard chest leads in both tracings show minor $\mathrm{T}$ wave notching only. However, the limb leads show $\mathrm{TI}<\mathrm{TIII}$, TaVL negative, and TaVF high, and the $R$ wave voltage in lead $I$ is greater than in lead III. These changes are more conspicuous in tracing $\mathrm{B}$. The high leads show abnormal $\mathrm{T}$ waves in leads $\mathrm{V} 1$ to $\mathrm{V} 5$ confirming underlying infarction in view of the clinical data.

$85 \cdot 7$ per cent (Table II). When the standard chest leads are normal, therefore, these reciprocal $\mathrm{T}$ wave changes in the limb leads are a valuable indicator for high chest leads in suspected cases of ischaemic heart disease. Moreover, an analysis of 818 serial cardiograms recorded from 332 cases of proven ischaemic heart disease over a period of five years shows an over-all incidence of 11.73 per cent of reciprocal $\mathrm{T}$ wave changes in the limb leads at some

TABLE II

INCIDENCE OF RECIPROCAL T WAVE CHANGES IN LIMB LEADS IN HIGH INFARCTION (TI < TIII, TaVL NEGATIVE, AND TaVF HIGH)

\begin{tabular}{|c|c|c|}
\hline Author & $\begin{array}{c}\text { No. of } \\
\text { cases }\end{array}$ & $\begin{array}{l}\text { Reciprocal } \\
\text { T changes }\end{array}$ \\
\hline $\begin{array}{l}\text { Rosenbaum et al. (1946) } \\
\text { Myers et al. (1949) } \\
\text { Schlant, Levine, and Bailey (1954) } \\
\text { Prinzmetal et al. (1957) } \\
\text { Roesler (1959) } \\
\text { Roesler and Fletcher (1963) } \\
\text { Fletcher, Morton, } \\
\text { Lal, and Murtagh }\} \text { (present series) }\end{array}$ & $\begin{array}{r}6 \\
3 \\
2 \\
5 \\
9 \\
6 \\
18\end{array}$ & $\begin{array}{r}4 \\
2 \\
1 \\
2 \\
9 \\
6 \\
18\end{array}$ \\
\hline Total & 49 & $42(86 \%)$ \\
\hline
\end{tabular}

stage in the sequential changes during the evolution of ischaemic changes in the cardiogram (Table III). These results are in keeping with the estimation of Prinzmetal et al. (1957) that small high infarctions account for about 10 per cent of all infarctions. It will be noted from Table III that the incidence of reciprocal $T$ wave changes in angina pectoris $(11.2 \%)$ and when subendocardial infarction developed $(0.09 \%)$ approximated to the over-all aver-

TABLE III

INCIDENCE OF RECIPROCAI T WAVE CHANGES IN LIMB LEADS IN ISCHAEMIC HEART DISEASE

\begin{tabular}{|c|c|c|c|c|}
\hline \multirow{2}{*}{ Diagnosis } & \multirow{2}{*}{$\begin{array}{l}\text { No. of } \\
\text { patients }\end{array}$} & \multicolumn{2}{|c|}{$\begin{array}{l}\text { Serial electro- } \\
\text { cardiograms } \\
\text { over } 5 \text { years }\end{array}$} & \multirow{2}{*}{$\begin{array}{c}\text { No. of } \\
\text { necropsies }\end{array}$} \\
\hline & & No. & $\begin{array}{c}\text { Reciprocal } \\
\text { T wave } \\
\text { changes } \\
(\%)\end{array}$ & \\
\hline $\begin{array}{l}\text { Angina pectoris } \\
\text { Antero-lateral infarction } \\
\text { Posterior infarction } \\
\text { Subendocardial infarction }\end{array}$ & $\begin{array}{r}60 \\
140 \\
112 \\
20\end{array}$ & $\begin{array}{r}196 \\
294 \\
284 \\
44\end{array}$ & \begin{tabular}{|c|}
$22(11 \cdot 2)$ \\
$58(19 \cdot 72)$ \\
$12(4 \cdot 22)$ \\
$4(9 \cdot 09)$
\end{tabular} & $\begin{array}{l}10 \\
62 \\
62 \\
10\end{array}$ \\
\hline Total & 332 & 818 & $96(11 \cdot 73)$ & 144 \\
\hline
\end{tabular}


age of 11.73 per cent. The much higher incidence of 19.72 per cent when antero-lateral infarction subsequently developed reflects the appearance and persistence of the reciprocal $T$ wave changes as manifestations of the healing phase of infarction. As may be anticipated, the evolution of posterior infarction tends to abolish the reciprocal $T$ wave changes, as reflected in the low incidence of $4 \cdot 22$ per cent (Table III).

The benign clinical course of small high infarctions makes necropsy correlation with cardiographic data unlikely unless the infarction extends to more conventional locations. Myers, Klein, and Stofer (1949) have defined the topography of these small high infarctions at necropsy. They are likely to be missed if the heart is dissected by the usual Virchow technique which is more suitable for the study of valve changes. Coronal sections of the ventricular muscle from apex to base permit a precise definition of the location of infarction. This technique was employed in 12 hearts of the 144 available in Table III. They were selected for study as the cardiograms showed reciprocal $T$ wave changes in the limb leads. In each instance involvement of the high lateral wall of the ventricles was confirmed (Roesler and Fletcher, 1963). Extensive atheroma with calcification and narrowing or occlusion of major coronary arteries was present in all the hearts examined. Involvement of a small branch of the descending left coronary artery at an early stage may explain the reciprocal $T$ wave changes in the limb leads and the diagnostic significance of high chest leads.

The reciprocal $T$ wave changes described in this paper as an indication for high chest leads for the identification of high lateral infarction are primary $T$ wave changes. Their significance will be invalidated if secondary $T$ wave changes are present as in intraventricular block or left ventricular hypertrophy, or if repolarization is altered by electrolyte imbalance or the action of drugs, especially digitalis. They have also been recorded in congenital heart disease, including ventricular septal defect and persistent ductus arteriosus, in displacement of the heart, and in meningo-encephalitis (Roesler and Fletcher, 1963, Fig. 10, 11, 117, 118, and 391). Correlation with clinical data is, therefore, essential for meaningful intepretation of these reciprocal $T$ wave changes in the limb leads in relation to ischaemic heart disease. Primary $T$ wave changes may be associated with myocardial necrosis due to infarction when abnormal $Q$ deflections are not present, either subendocardial (Pruitt, Klakeg, and Chapin, 1955), septal (Abrahams, 1957), or intramural (Cutts, Merlino, and Easton, 1957). None of our patients had abnormal $Q$ deflections in the limb leads, though it should be noted that infarction of the postero-septal wall of the ventricles is characterized by their absence in antero-lateral leads (Burch, 1956). Abnormal Q deflections may appear in the high chest leads in high lateral infarction and subsequently disappear, as exemplified in Fig. 2 (Benchimol, Schlesinger, and Cotrim, 1947). The explanation may be the shrinkage of the small area of infarction in the healed phase. In conclusion, sequential cardiographic studies in ischaemic heart disease may reveal TI $<$ TIII, TaVL negative, and TaVF high, when the mean QRS axis is normally directed or directed leftwards with normal conventional chest leads. These changes may indicate that at the time of observation the ischaemic lesion is isolated in the high lateral position in the ventricles, which may be confirmed by recording additional high chest leads in the third intercostal space.

\section{SUMMARY}

During the evolution of ischaemic heart disease sequential cardiograms may show minor primary $\mathrm{T}$ wave abnormalities in the limb leads $\mathrm{TI}<\mathrm{TIII}$, TaVL negative, and TaVF high, when the infarction is small and located at a high level in the anterolateral wall of the ventricles. If the conventional chest leads are normal, the diagnosis of infarction may be confirmed by additional high chest leads in the third intercostal space. Eighteen cases of high lateral infarction are described. Correlation of cardiographic findings in cases of myocardial infarction indicates that about 10 per cent of serial tracings may show the $T$ wave changes noted above, which, therefore, provide a useful indication for additional chest leads. They are particularly valuable when the evidence of ischaemic heart disease appears inconclusive.

\section{REFERENCES}

Abrahams, D. G. (1957). Septal infarction with recovery of the electrocardiogram. Brit. Heart f., 19, 233.

Benchimol, A. B., Schlesinger, P., and Cotrim, M. R. (1947). Regression de las alteraciones del QRS en el infarcto alto dela pared anterior. Rev. argent. Cardiol., 14, 369.

Burch, G. E. (1956). An electrocardiographic syndrome characterized by absence of $Q$ in leads $I, V 5$ and V6. Amer. Heart f., 51, 487.

Cutts, F. B., Merlino, F., and Easton, F. W. (1957). Chest pain with inverted $T$ waves, predominantly in precordial leads, as the only electrocardiographic abnormality. Circulation, 16, 599.

Dressler, W. (1943). Myocardial infarction indicated by an electrocardiographic pattern in which $T I$ is lower than T3. Report of 45 cases. Amer. Heart F., $26,313$.

Goldberger, E. (1947). The relations of TI and T3. Amer. Heart F., 34, 395.

Grant, R. P. (1957). Clinical Electrocardiography. McGrawHill, New York. 
Holtzmann, M. (1952). Clinical Electrocardiography-A Text-Book for Practitioners and Students. Trans. by D. Robertson. Staples, London.

Myers, G. B., Klein, H. A., and Stofer, B. E. (1949). Correlation of electrocardiographic and pathologic findings in lateral infarction. Amer. Heart $\mathcal{F}$., 37, 374.

Prinzmetal, M., Kennamer, R., and Massumi, R. (1957). High anterior myocardial infarction. XX. Studies on the mechanism of ventricular activity. Circulation, 15, 575.

Pruitt, R. D., Klakeg, C. H., and Chapin, L. E. (1955). Certain clinical states and pathologic changes associated with deeply inverted $\mathrm{T}$ waves in the precordial electrocardiogram. Circulation, 11, 517.

Roesler, H. (1959). High chest leads and minor myocardial infarctions. Brit. Heart f., 21, 407.

-, and Fletcher, E. (1963). An Atlas of Electrocardiography. Wright, Bristol.

Rosenbaum, F. F., Wilson, F. N., and Johnston, F. D. (1946). The precordial electrocardiogram in high lateral myocardial infarction. Amer. Heart f., 32, 135.

Schlant, R. C., Levine, H. D., and Bailey, C. C. (1954), "Isolated" T-wave negativity in the "ischemic phase" of myocardial infarction in men. Circulation, 10, 829. 